\title{
Genetic transformation technologies for the common dandelion, Taraxacum officinale
}

\author{
Kasia Dinkeloo* ${ }^{*}$, Araceli Maria Cantero, Inyup Paik, Alexa Vulgamott, Andrew D Ellington and Alan Lloyd
}

\begin{abstract}
Background: Taraxacum officinale, or the common dandelion, is a widespread perennial species recognized worldwide as a common lawn and garden weed. Common dandelion is also cultivated for use in teas, as edible greens, and for use in traditional medicine. It produces latex and is closely related to the Russian dandelion, T. kok-saghyz, which is being developed as a rubber crop. Additionally, the vast majority of extant common dandelions reproduce asexually through apomictically derived seeds- an important goal for many major crops in modern agriculture. As such, there is increasing interest in the molecular control of important pathways as well as basic molecular biology and reproduction of common dandelion.

Results: Here we present an improved Agrobacterium-based genetic transformation and regeneration protocol, a protocol for generation and transformation of protoplasts using free DNA, and a protocol for leaf Agrobacterium infiltration for transient gene expression. These protocols use easily obtainable leaf explants from soil-grown plants and reagents common to most molecular plant laboratories. We show that common markers used in many plant transformation systems function as expected in common dandelion including fluorescent proteins, GUS, and anthocyanin regulation, as well as resistance to kanamycin, Basta, and hygromycin.
\end{abstract}

Conclusion: Reproducible, stable and transient transformation methods are presented that will allow for needed molecular structure and function studies of genes and proteins in T. officinale.

Keywords: Dandelion, Transformation, Transient expression, Protoplast transformation, Taraxacum officinale

\section{Introduction}

The use of model organisms to understand genome-tophenome problems has enjoyed undisputed success for decades. The ability to study and understand biological phenomena has been driven by the development of technologies using these models as foils for the rest of life. There has always been work using "non-model" organisms, but often this work has been hampered by the paucity of tools to manipulate genes and genomes, or to even know what genes are present.

*Correspondence: kdinkeloo@utexas.edu; amlloyd@utexas.edu Department of Molecular Biosciences, College of Natural Sciences, The University of Texas at Austin, Austin, TX 78712, USA

\section{Why study dandelion?}

Taraxacum officinale or the common dandelion is a weedy perennial that is extremely widely distributed in the biosphere. Although it's center of distribution is Eurasia, it occurs from the tropics to the temperate zones in the northern and southern hemispheres. While it is native to the old world, like most weeds it has spread with human activity. Dandelion is a minor vegetable crop with the greens eaten cooked or fresh and the roots made into tea. The blossoms are made into the widely familiar Dandelion Wine. Dandelion can be immediately identified by anyone who has gardened or tried to maintain a lawn.

Several labs are working on various aspects of common dandelion biology. Examples include genome size and ploidy determinations for hundreds of accessions 
[1]; mapping of genes that control aspects of apomixis [2-4]; and determining the bioactivity of extracts and compounds in various medically relevant treatments and their possible benefits for human nutrition [5-10].

Common dandelion is robust. It is easy to culture under growth chamber, greenhouse, and garden conditions (Fig. 1a). Genetic transformation is a must in order to do modern genotype to phenotype studies. There are several published protocols for stable transformation of Taraxacum kok-saghyz, T. brevicorniculatum, and T. platycarpum [11-13] and a single publication describes transformation of $T$. officinale [14]. Here, we have modified these protocols for simplification of explant source and in vitro manipulation of common dandelion. We use soil grown leaf piece explants, co-cultivate with Agrobacterium, then callus and regenerate shoots on a single hormone regime. We then induce rooting of regenerated shoots on another hormone regime, and subsequently transfer to soil. The process takes as little as 12 weeks from explant to soil and then another six to eight weeks to flower. We have successfully used three available selectable markers: resistance to kanamycin; hygromycin; and Basta. Additionally, Basta herbicide resistance provides for easy and cheap transformant and
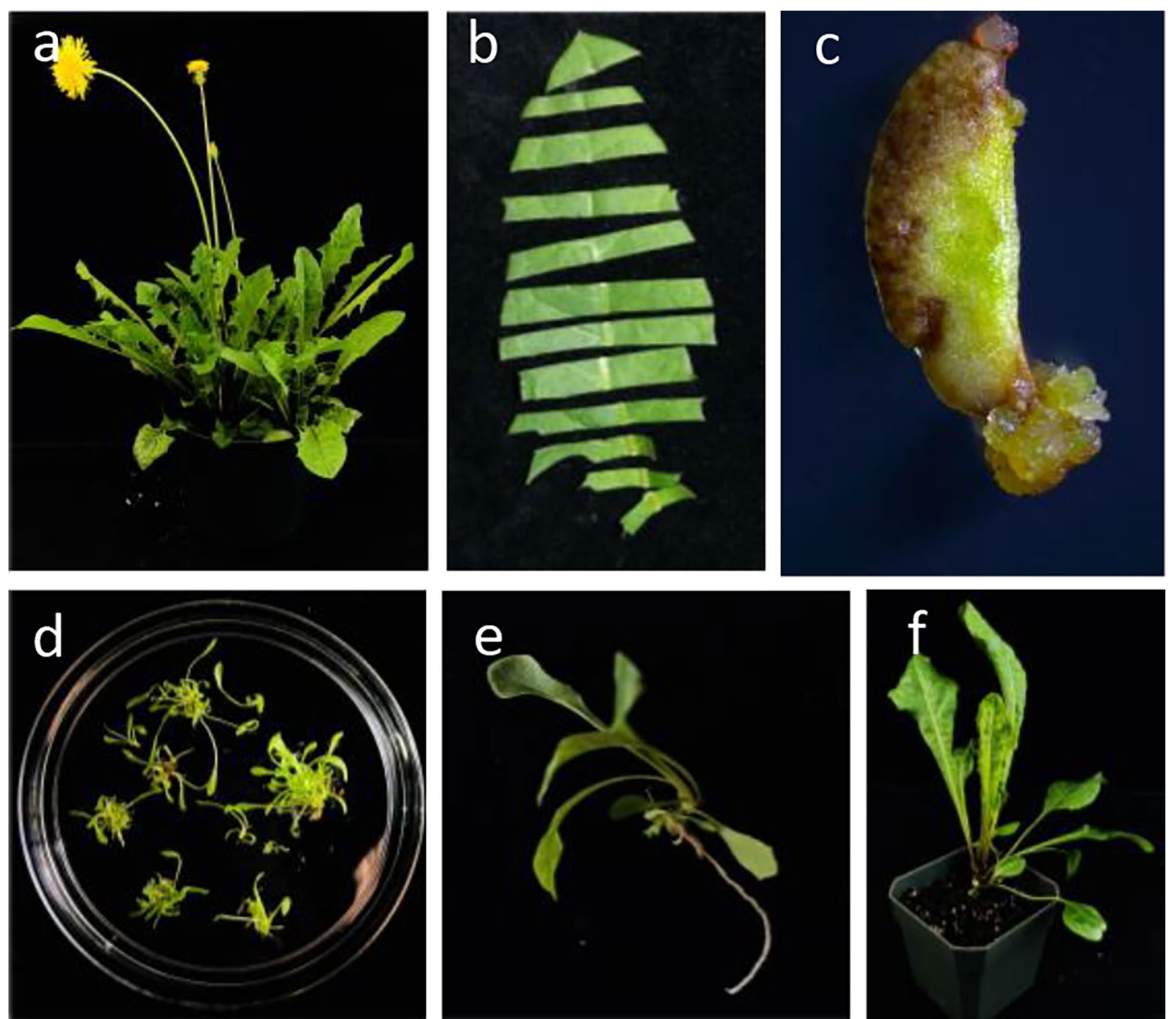

Fig. 1 Stages of Dandelion transformation. a Flowering dandelion plant grown on soil in a growth chamber. b Common dandelion leaf cut into explants for transformation via tissue culture. c Transgenic callus growing from a leaf explant. $\mathbf{d}$ Plantlet stage of transformation in which small groups of leaves grow from the callus. e Rooting occurs at variable times during the plantlet stage. f Transgenic dandelion are moved to soil after roots are present 
progeny screening in soil. We have shown that GUS and fluorescent protein markers function well in common dandelion. To provide an additional visual marker, we have shown that the anthocyanin pathway can be upregulated in dandelion with the MYB113 anthocyanin regulator from Arabidopsis, resulting in deep purple leaves [15]. To complement stable genetic transformation, we have developed leaf infiltration (à la Nicotiana benthamiana [16]) as a method for quickly and transiently assaying gene function. Further, we developed a protocol to perform protoplast transformation using free DNA for possible large-scale screening technologies.

\section{Materials and methods}

\section{Agrobacterium and constructs used in transformation experiments}

Agrobacterium-based experiments were performed using Agrobacterium tumefaciens strain GV3101 pMP90 [17]. The following plasmids were used: pGFPGUSPlus [18]; Addgene plasmid \# 64401; contains CaMV35Sdriven hygromycin resistance, EGFP reporter, and GUS reporter; pMYB113 [15]; contains NOS promoter driven hygromycin resistance, CaMV35S:Arabidopsis MYB113; pPM-YB [19]; contains plasma membrane localized YFP, Mannopine Synthase Promoter:phosphinothricin (Basta) acetyl transferase; pEZS-CL [20]; a high copy plasmid containing CaMV35S:EGFP.

For the leaf infiltration experiments, we also included the RNA silencing suppressor, P19 in Agrobacterium strain GV 3101 [21]. Agrobacterium and E. coli strains were maintained on LB media with appropriate antibiotics to select for the plasmids and Rifampicin $10 \mathrm{mg} / \mathrm{L}$ and Gentamycin $30 \mathrm{mg} / \mathrm{L}$ to select for Agrobacterium GV3101 pMP90 [17].

\section{Agrobacteriummediated transformation and regeneration of common dandelion}

Young leaves (10 to $15 \mathrm{~cm}$ long) were excised from soil grown plants and placed in $10 \%$ bleach with $0.04 \%$ Tween 20 for $10 \mathrm{~min}$ for surface sterilization, and then rinsed 4 times in sterile water. The Agrobacterium solution was prepared from overnight Agrobacterium cultures grown in $5 \mathrm{~mL}$ LB media under antibiotic selection. These cultures were pelleted via centrifugation at $3000 \times \mathrm{g}$ for $10 \mathrm{~min}$. The pellet was resuspended in induction solution (1XMS, 3\% Sucrose, 1\% Glucose, $0.2 \mathrm{mM}$ acetosyringone, $\mathrm{pH}$ 5.2) as a first wash, and then pelleted and resuspended a second time in $5 \mathrm{~mL}$ induction solution. The Agrobacterium in induction solution was then incubated at $30{ }^{\circ} \mathrm{C}$ with agitation for 1 hour. Leaves were cut into strips approximately $0.75 \mathrm{~cm}$ long spanning the width of the leaf. The leaf strips were placed into an empty petri dish, and the Agrobacterium induction solution was added to the leaf strips with gentle agitation for an incubation period of $5 \mathrm{~min}$. These strips were gently tapped on an empty petri dish to remove excess Agrobacterium induction solution, and placed adaxial side up on petri plates containing cocultivation media (1XMS, 3\% sucrose, $1 \%$ glucose, $0.1 \mathrm{mM}$ acetosyringone $+2 \mathrm{mg} / \mathrm{L}$ BAP, $0.1 \mathrm{mg} / \mathrm{L}$ NAA, 0.9\% agar pH 5.2). Petri dishes were sealed with micropore tape and leaf pieces and Agrobacterium were co-cultivated for 2 days in darkness at $26^{\circ} \mathrm{C}$. After co-cultivation, leaf pieces were moved to media containing 1XMS, 3\% sucrose, + $2 \mathrm{mg} / \mathrm{L} \mathrm{BAP,} 0.1 \mathrm{mg} / \mathrm{L}$ NAA, $300 \mathrm{mg} / \mathrm{L}$ Timentin, 0.9\% agar pH 5.2 and sealed with parafilm.

After 7 days, the leaf pieces were transferred to shoot induction media (1XMS, 3\% sucrose, $2 \mathrm{mg} / \mathrm{L}$ BAP, $0.1 \mathrm{mg} / \mathrm{L}$ NAA, $0.9 \%$ agar, $300 \mathrm{mg} / \mathrm{L}$ Timentin, $\mathrm{pH}$ 5.7) containing the appropriate antibiotic or herbicide to select for transformed dandelion cells. We used $100 \mathrm{mg} / \mathrm{L}$ kanamycin, $50 \mathrm{mg} / \mathrm{L}$ hygromycin, or $3 \mathrm{mg} / \mathrm{L}$ Basta (phosphinothricin), all from Sigma. When leaves on shoots were approximately $1.5-2 \mathrm{~cm}$ long, they were transferred to the same media but with $0.1 \mathrm{mg} / \mathrm{L} \mathrm{NAA}$ to elicit root differentiation. Shoots with well-formed roots at least $1.5 \mathrm{~cm}$ long were transferred to soil (Promix BX; Hummert International) and placed in flats with transparent lids to keep the humidity high. Once new leaf growth was observed, the lids were gradually removed.

\section{Genotyping of transgenic dandelion; inheritance of TDNA in progeny of primary transformants}

PCR amplification of sequences on the Agrobacterium TDNA was used to assess whether potential regenerated transformants indeed contained the transgene. PCR primers and the size of the expected DNA fragments are listed in Table 1. Genomic DNA was isolated from dandelion using the CTAB method [22], using 10-15 mg of tissue from leaves that emerged after the plants were transferred to soil or from tissue from the next generation seedlings. To test for markers in transgenic progeny, seeds were sown in $10 \mathrm{~cm}$ square pots on the soil surface

Table 1 List of primers for genotyping analysis of dandelion

\begin{tabular}{lll}
\hline Primer name & The sequence $\left(\mathbf{5}^{\prime} \mathbf{- 3}^{\prime} \mathbf{)}\right.$ & $\begin{array}{l}\text { Length of } \\
\text { product } \\
\mathbf{( b p )}\end{array}$ \\
\hline ACTIN-F & CGTCGATCTCAAGGATGTTGTC & 120 \\
ACTIN-R & GGAGCTTTGAGAAGAACCAACG & \\
YFP-F & ATGGTGAGCAAGGGCG & 300 \\
YFP-R & TTGTACAGCTCGTCCATGC & \\
BASTA-F & AAACCCACGTCATGCCAGTT & 343 \\
BASTA-R & AAGCACGGTCAACTTCCGTA & \\
\hline
\end{tabular}


(promix BX) and grown at $24{ }^{\circ} \mathrm{C}$ under fluorescent lights with a 16/8 h light/dark cycle.

\section{Basta herbicide resistance assay}

For Basta herbicide resistance assays, seeds were sown as above and 10 to 14 day old wildtype or Basta resistant seedlings grown in 2.5 inch pots were treated with $25 \mathrm{ml}$ of $3 \mathrm{mg} / \mathrm{l}$ Basta, results were collected 7 days after exposure.

\section{Agrobacterium mediated leaf-infiltration for transient gene expression}

The bacteria grown as above and were harvested by centrifugation for $3 \mathrm{~min}$ at $3000 \times \mathrm{g}$. The pellets were rinsed by resuspension in the same volume of infiltration buffer (10 $\mathrm{mM} \mathrm{MgCl}, 10 \mu \mathrm{M}$ acetosyringone) and centrifuged again for $3 \mathrm{~min}$ at $3000 \times \mathrm{g}$. Pellets were again resuspended in infiltration buffer. The $\mathrm{OD}_{600}$ was measured and each strain was diluted to $\mathrm{OD}_{600}$ of 0.1 with infiltration buffer. Each infiltration experiment contained two Agrobacterium strains: one strain contained the transient gene expression construct and the other contained the RNA silencing suppressor, P19 [21].

Young dandelion plants approximately four weeks of age were used for infiltration. The bacterial suspension was infiltrated into the abaxial leaf surface using a $1 \mathrm{ml}$ tuberculin syringe without needle in the method of Vaghchhipawala et al. [16]. Briefly, the syringe tip is held tightly to the abaxial leaf surface and a gloved finger is held on the opposite adaxial side while the syringe plunger is gently but firmly pushed forcing the Agrobacterium solution into the leaf interior. 3-5 days post infiltration the leaf was excised from the plant and transient gene expression was tested by either GUS staining according to Jefferson et al. [23], observing YFP fluorescence under a fluorescent microscope, or visual inspection for anthocyanin accumulation in the infiltrated area.

\section{Protoplast preparation}

Two incubation regimes were tested: $30{ }^{\circ} \mathrm{C}$ for 3 hours and $22{ }^{\circ} \mathrm{C}$ for 15 to $17 \mathrm{~h}$. For the $30{ }^{\circ} \mathrm{C}$ treatment, the enzyme solution was prepared as follows, $20 \mathrm{mM}$ MES (pH 5.7), $0.5 \mathrm{M}$ mannitol, $20 \mathrm{mM} \mathrm{KCl}$, cellulase R10 1.0\% wt/vol (Yakult Pharmaceutical Industry Co., Ltd), macerozyme R10 0.5\% wt/vol (Yakult Pharmaceutical Industry Co., Ltd). This enzyme solution was heated to $60{ }^{\circ} \mathrm{C}$ for 5 minutes and cooled to room temperature. $\mathrm{CaCl}_{2}$ was added to $10 \mathrm{mM}$ and BSA to $0.1 \%$. The $22{ }^{\circ} \mathrm{C}$ treatment used the same solutions except for $0.45 \% \mathrm{wt} / \mathrm{vol}$ cellulase R10, $0.2 \% \mathrm{wt} / \mathrm{vol}$ macerozyme R10.

Protoplasts were prepared from the 3rd to 5 th leaves (approximately 5 to $6 \mathrm{~cm}$ long) from 3 to 4 -week old dandelion plants. Dandelion leaves were detached from the plants and lightly scratched with sandpaper (3M 413Q, 220 grit) on the abaxial side before immediate submersion in $10 \mathrm{ml}$ of enzyme solution. They were incubated at either $22{ }^{\circ} \mathrm{C}$ overnight or $30{ }^{\circ} \mathrm{C}$ for $3 \mathrm{~h}$ in the dark in $10 \mathrm{~cm}$ petri dishes. After the incubation period, $10 \mathrm{ml}$ of W5 solution ( $2 \mathrm{mM}$ MES pH 5.7, $154 \mathrm{mM} \mathrm{NaCl}, 125 \mathrm{mM}$ $\mathrm{CaCl}_{2}, 5 \mathrm{mM} \mathrm{KCl}$ ) was then added to the enzyme solution to stop the reaction. The $20 \mathrm{ml}$ reaction mix was filtered through a $100 \mu \mathrm{m}$ cell strainer (Fisher Scientific., Cat\# 22-363-549) and split into two $15 \mathrm{ml}$ round bottom tubes. The protoplasts were collected by centrifuging for $2 \mathrm{~min}$ at $1000 \times \mathrm{g}$. The supernatant was removed by pipetting as much liquid as possible while leaving the pellet intact in the tube. The green pellets were resuspended by adding $2 \mathrm{ml}$ of W5 solution and the tubes were incubated on ice for $30 \mathrm{~min}$.

The cell number was counted using a hemocytometer. The protoplasts were resuspended at $5 \times 10^{5}$ cells $/ \mathrm{ml}$ in MMG solution (4 mM MES pH 5.7, 0.4 M mannitol, $15 \mathrm{mM} \mathrm{MgCl}_{2}$ ) prior to transformation. Protoplast viability after isolation was analyzed using the fluorescein diacetate staining method described by Larkin [24].

\section{Free DNA delivery to protoplasts}

A total of $10 \mu \mathrm{g}$ of plasmid DNA (pEZS-CL) at 1.5 to $3 \mu \mathrm{g} / \mu \mathrm{L}$ concentration was added to $100 \mu \mathrm{l}$ of MMG resuspended protoplasts and this was gently mixed before adding $100 \mu \mathrm{l}$ of PEG transformation solution (30\% wt/vol PEG4000 (Sigma Aldrich., Cat\# 95904), $0.2 \mathrm{M}$ mannitol, $100 \mathrm{mM} \mathrm{CaCl} 2)$ for $5 \mathrm{~min}$. The transformation reaction was stopped by adding $20 \mathrm{ml}$ of W5 solution and the protoplasts were collected by centrifugation for $2 \mathrm{~min}$ at $1000 \mathrm{~g}$. Transformed protoplasts were incubated at $22{ }^{\circ} \mathrm{C}$ for 15 to $17 \mathrm{~h}$ in WI solution (4 mM MES pH 5.7, $0.5 \mathrm{M}$ mannitol, $20 \mathrm{mM} \mathrm{KCl}$ ) before the GFP signal was detected.

\section{Observation of fluorescent protein or GUS expression}

YFP or GFP protein fluorescence was observed on an Olympus BX53 microscope with a YFP or GFP filter at $10 \mathrm{x}$ with a 1 second exposure. GUS staining was done according to Jefferson et al. [23].

\section{Results}

\section{Stable transformation and regeneration}

In order for any plant to truly submit to molecular analysis there must be a reliable transformation and regeneration protocol to produce stable whole transgenic plants. We developed a protocol modified from previous Taraxacum researchers [11-14]. We began by trying to use aseptic explants from seedlings germinated and grown in sterile culture. While we were able to transform explants from these seedlings, it is much less labor and resource 
intensive to surface sterilize leaves from soil grown plants (Fig. 1a). Explants were prepared but cutting sterilized leaves into strips (Fig. 1b). Uninoculated explants will differentiate shoots in as little as 20 days in the absence of selection on MS media containing $2 \mathrm{mg} / \mathrm{L}$ BAP, $0.1 \mathrm{mg} / \mathrm{L}$ NAA. In the presence of Basta and hygromycin selection, most uninoculated explants do not give rise to callus or differentiate. Under kanamycin selection some explants will give rise to bleached white callus and leaves. With Agrobacterium inoculation and selection, we found that transgenic callus most often emerged from the explant edges at the site of major veins after 15 to 20 days (Fig 1c). Shoots typically emerged from these calli in 5 to 6 weeks (Fig. 1d, e). Three selection markers were successfully used to select for transgenic plant cells and plants: kanamycin, hygromycin, and Basta resistance. The percentage of leaf explants that produced transgenic callus and shoots was: 32\% for Basta, 23\% for kanamycin, and $\sim 30 \%$ for hygromycin (Table 2 ). Most explants gave multiple independent foci of transformation. As a rule, we only retained one transgenic plant from each explant to ensure we were observing independent events. Transgenic shoots were rooted on MS media with $0.1 \mathrm{mg} / \mathrm{L}$ NAA before being transferred to soil. The timing for rooting of shoots was quite variable, from as short as 6 weeks to as long as 16 weeks. Genotyping was done on leaves that were newly emerged after the transition to soil, although transformation of dandelion using the Arabidopsis MYB113 transcription factor was readily visible with the naked eye by observing the induction of $\mathrm{red} /$ purple anthocyanin pigment synthesis (Fig. 2a). We have repeated these transformation/regeneration experiments many times, however, transformation frequency data was only collected from 2 experiments with each for Basta and kanamycin selection, and a single experiment for hygromycin selection (Table 2).

The seeds of transgenic dandelions were collected and germinated to understand the heritability of transgenes. Fig. 2b presents the inheritance of the Basta resistance marker gene and YFP marker gene in transgenic

Table 2 Transformation efficiency of leaf explants under different selection

\begin{tabular}{lcll}
\hline Selection & Explant \# & Transformant \# & T efficiency\% \\
\hline Basta I & 94 & 30 & 32 \\
Basta II & 36 & 11 & 31 \\
Kanamycin I & 113 & 21 & 19 \\
Kanamycin II & 36 & 10 & 28 \\
Hygromycin & 89 & 27 & 30 \\
& & Average \% \pm st. dev. & $27.9 \pm 7.23$ \\
\hline
\end{tabular}
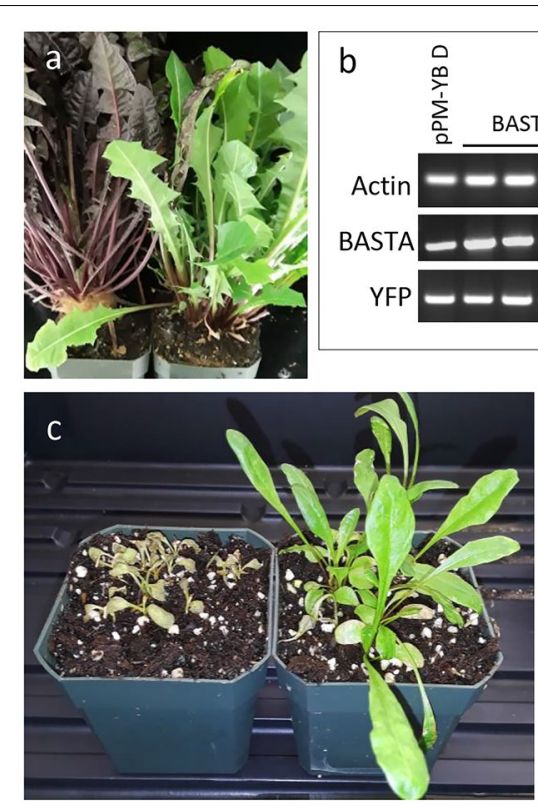

Fig. 2 Inheritance of TDNA in progeny of primary transformants. a Induction of red/purple anthocyanin pigment from expression of the Arabidopsis MYB113 transcription factor shown in transgenic dandelion (left) versus no pigment in wild type plants (right). $\mathbf{b}$ Amplification of Agrobacterium TDNA sequences for Basta resistance and YFP present in transgenic parental plant and seedlings and absent in WT. cWT seedlings (left) are killed by treatment with Basta herbicide, Basta-resistant seedlings (right) are unaffected. $\mathbf{d}$ Fluorescent microscopy of WT shows no fluorescence. $\mathbf{e}, \mathbf{f}$ Transgenic seedlings show YFP fluorescence in mesophyll and epidermal cells respectively

offspring. Amplified bands were separated and observed using agarose gel electrophoresis, and bands confirming the presence of YFP and Basta were apparent for the parental plant and all offspring, but not for the wild type plant. To confirm the activity of the transgenes, wildtype seedlings and Basta resistant seedlings were treated with $3 \mathrm{mg} / \mathrm{l} \mathrm{Basta}$. Wild-type seedlings are killed by the herbicide, while transgenic progeny are resistant (Fig. 2c). The seedlings were also tested for YFP expression where fluorescent microscopy shows the transgenic seedlings expressing active YFP fluorescence, and the wild type seedlings do not (Fig. 2d, e, f).

\section{Agrobacterium mediated leaf-infiltration for transient gene expression}

Infiltration of leaves with Agrobacterium tumefaciens is often used as a transient assay for gene expression studies. While Nicotiana benthamiana is the most commonly used species for this technology, methods have been worked out for many others $[25,26]$. The protocol we present here is based on $N$. benthamiana methods [16]. We successfully infiltrated constructs into the 
abaxial side of dandelion leaves. We were able to observe both YFP and GUS reporter gene expression (Fig. 3) 3 to 5 days after treatment.

\section{Protoplast transformation}

Protoplast transformation can provide a means to test transformation constructs or to screen inducers or inhibitors, or perform other assays in a fast and high throughput manner $[9,27]$. To establish a protoplast transformation system, we examined whether common dandelion leaf tissue could be efficiently digested with the enzymes commonly used for mesophyll protoplast isolation in Arabidopsis [9]. With slight modifications in enzyme concentrations and buffer conditions, we were able to isolate intact protoplasts from 3 to 4-week old dandelion leaves (Fig. 3e). As reported previously for switchgrass [27] the age of the plants affected the cell wall digestion efficiency, with leaves from older plants being more difficult to digest and producing a lower yield of protoplasts. Therefore, we only selected the 3rd to 5th leaf from 3 to 4-week old dandelions for the preparation of protoplasts. The protoplasts were assayed for viability using fluorescein diacetate staining, with an average of $75.2 \%( \pm 1.7)$ of protoplasts maintaining viability after extraction (Table 3). We then performed PEG-based protoplast transformation as described above and observed the cells for fluorescence at 15 to $17 \mathrm{~h}$ post transformation (Fig. 3f). We examined the effect of three different concentrations of PEG (20,30, and 40\%) on protoplast transformation efficiency because others have reported that PEG concentration was an important variable [27]. We found that protoplasts were successfully transformed with all concentrations. The 30\% PEG protocol gave up to $40 \%$ transformation efficiency, while $20 \%$ and $40 \%$ PEG protocols provided a transformation efficiency of up to 25\% (Fig. 3g). These efficiencies are sufficient for most

Table 3 Protoplast viability

\begin{tabular}{llll}
\hline Replicate & $\begin{array}{l}\text { Viable } \\
\text { Protoplasts }\end{array}$ & Total Protoplasts & Viability (\%) \\
\hline 1 & 66 & 86 & 76.7 \\
2 & 58 & 77 & 75.3 \\
3 & 69 & 94 & 73.4 \\
& & Average \% & 75.2 \\
& & \pm & 1.7 \\
\hline
\end{tabular}
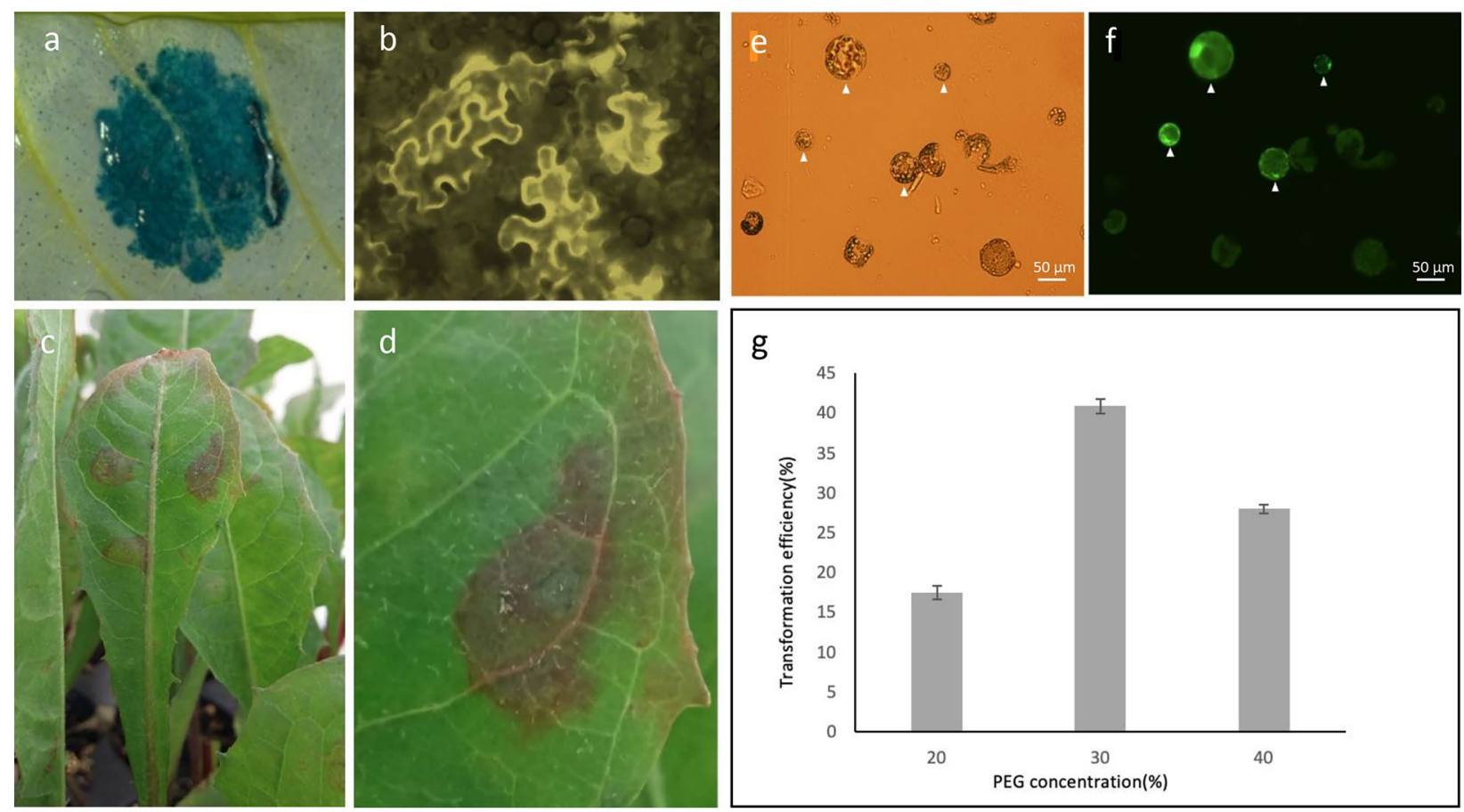

Fig. 3 Transient gene expression and protoplast transformation in Common Dandelion. When using different reporter constructs in Agrobacterium, transient expression is achieved as shown by: a GUS staining, b YFP fluorescence, and $\mathbf{c}$ anthocyanin accumulation. e Transformed dandelion protoplasts shown with light microscopy. f fluorescent microscopy shows activity of the YFP reporter gene in transgenic protoplasts. $\mathbf{g}$ Transformation efficiencies resulting from different concentrations of PEG. Each PEG concentration experiment was repeated three times. Error bars represent standard deviation 
assay applications and as they stand can easily be adapted for automated liquid handling.

\section{Discussion}

There are many important qualities that make the common dandelion an appealing research subject. It is easy to cultivate in many environmental conditions from growth chambers and greenhouses to the field, and it produces many progeny per composite flower head. Other qualities include: a largely apomictic lifestyle, its use as a vegetable for greens, the use of its roots in teas and flowers in wine, its use in traditional and modern medical studies, and finally, the ability to make latex and its close relationship to the latex/rubber producing Russian dandelion.

We note here that increasing numbers of "non-model" plants are being tamed for specific genomic engineering opportunities often based on desirable idiosyncratic properties. These include developmental patterns, physiologies, or secondary metabolic pathways. The common dandelion abounds in all of these with its rosette form with taproot, its family-typical composite flower head, its largely apomictic reproduction mode, and its many potentially valuable secondary metabolic pathways.

As an example, several groups are working on the closely related Russian or rubber dandelion, Taraxacum kok-saghyz (a few recent examples include: [28-33], with the goal to develop it as a natural rubber production crop to backup or replace the rubber tree, a crop with a troubled past and future [34, 35]. Rubber production from latex in Russian dandelion is often extolled in popular media [36], however, T. kok-saghyz is a species with a very narrow distribution, endemic only in southeast Kazakhstan, and it has exacting culture requirements [34]. As a latex-producer related to Russian dandelion, the "genome-enabling" of common dandelion could lead to synthetic biology approaches where efficient rubber production is engineered into this much more agriculturally facile species, or its facile properties engineered or hybridized into the Russian dandelion. The natural rubber market produced 14 million metric tons in 2018 up from 8.3 million metric tons in 2004 and the demand is expected to continue to rise [37, 38]. Much could be gained by leveraging common dandelion in the cause of an alternative commercial source for natural rubber.

In order to genomically enable the common dandelion, many tools will need to be developed for this species. These tools would include robust annotated transcriptome and genome sequences, the ability to do traditional genetics, the ability to facilely transform the plant both stably and transiently, and the ability to create knockdown or loss-of-function mutants.

Here we present simple methods for transient transformation of dandelion leaves and protoplasts, and for stable transformation and regeneration of plants. We have shown that the common dandelion is amenable to common techniques used in many other species. A few improvements our protocol offers include a dandelion explant source that is easily grown on soil in conditions we use for Arabidopsis thaliana, and one hormone regime for stable transformation and regeneration and another for rooting shoots. Our data show that at least three selection regimes are possible including kanamycin, hygromycin, and Basta resistance. We also found that standard markers function as expected in dandelion including: YFP, GFP, GUS, and MYB regulation of the anthocyanin pathway. In this manuscript we present transformation efficiency, timeline, and optimization efforts, providing important information for those attempting transformation of common dandelion

In conclusion, we describe a set of protocols that will help make the common dandelion amenable to modern techniques used in other model species. Any lab that has the facilities to do molecular work in Arabidopsis or Nicotiana, for example, will be able to perform the same work in common dandelion.

\section{Acknowledgements}

The work presented here was sponsored by the Defense Advanced Research Projects Agency. The content of the information does not necessarily reflect the position or the policy of the Government, and no official endorsement should be inferred. We thank members of the DARPA-APT team for generous feedback on experimental methods.

\section{Authors' contributions}

AGC established the stable transformation protocol and tested explant source and antibiotic selections. KD established the stable transformation protocol, the transient expression assay, performed microscopy and analysis of transformant data, and was a major contributor in writing the manuscript. IP established the protoplast transformation protocol. AV maintained tissue cultures and plant transformants. AE was a major contributor in writing the manuscript. AL established the stable transformation protocol, maintained plant lines, tested herbicide tolerance, provided oversight and experimental framework, and was a major contributor in writing the manuscript. All authors have read and approved the final manuscript.

\section{Funding}

The work presented here was sponsored by the Defense Advanced Research Projects Agency. The content of the information does not necessarily reflect the position or the policy of the Government, and no official endorsement should be inferred.

\section{Availability of data and materials}

The datasets used and/or analyzed during the current study are available from the corresponding author on reasonable request.

\section{Declarations}

Ethics approval and consent to participate Not applicable

Consent for publication

Not applicable'

Competing interests

The authors declare that they have no competing interests. 
Received: 10 February 2021 Accepted: 27 May 2021

Published online: 09 June 2021

\section{References}

1. laffaldano BJ, Zhang Y, Cardina J, Cornish K. Genome size variation among common dandelion accessions informs their mode of reproduction and suggests the absence of sexual diploids in North America. Plant Syst Evol. 2017;303(6):719-25.

2. van Dijk PJ, Bakx-Schotman JM. Formation of unreduced megaspores (diplospory) in apomictic dandelions (Taraxacum officinale, s.l.) is controlled by a sex-specific dominant locus. Genetics. 2004;166(1):483-92.

3. Vašut RJ, Vijverberg K, van Dijk PJ, de Jong H. Fluorescent in situ hybridization shows DIPLOSPOROUS located on one of the NOR chromosomes in apomictic dandelions (Taraxacum) in the absence of a large hemizygous chromosomal region. Genome. 2014;57(11-12):609-20.

4. Vijverberg K, Milanovic-Ivanovic S, Bakx-Schotman T, van Dijk PJ. Genetic fine-mapping of DIPLOSPOROUS in Taraxacum (dandelion; Asteraceae) indicates a duplicated DIP-gene. BMC Plant Biol. 2010;10:154

5. Hu C, Kitts DD. Antioxidant, prooxidant, and cytotoxic activities of solvent-fractionated dandelion (Taraxacum officinale) flower extracts in vitro. J Agric Food Chem. 2003;51(1):301-10.

6. Escudero NL, De Arellano ML, Fernández S, Albarracín G, Mucciarelli S. Taraxacum officinale as a food source. Plant Foods Hum Nutr. 2003;58(3):1-10.

7. Jeon HJ, Kang HJ, Jung HJ, Kang YS, Lim CJ, Kim YM, et al. Anti-inflammatory activity of Taraxacum officinale. J Ethnopharmacol. 2008;115(1):82-8.

8. Sigstedt SC, Hooten CJ, Callewaert MC, Jenkins AR, Romero AE, Pullin $\mathrm{MJ}$, et al. Evaluation of aqueous extracts of Taraxacum officinale on growth and invasion of breast and prostate cancer cells. Int J Oncol. 2008;32(5):1085-90.

9. You Y, Yoo S, Yoon HG, Park J, Lee YH, Kim S, et al. In vitro and in vivo hepatoprotective effects of the aqueous extract from Taraxacum officinale (dandelion) root against alcohol-induced oxidative stress. Food Chem Toxicol. 2010;48(6):1632-7.

10. Sharifi-Rad M, Roberts TH, Matthews KR, Bezerra CF, Morais-Braga MFB, Coutinho HDM, et al. Ethnobotany of the genus Taraxacum — phytochemicals and antimicrobial activity. Phytother Res. 2018;32(11):2131-45.

11. Bae TW, Park HR, Kwak YS, Lee HY, Ryu SB. Agrobacterium tumefaciensmediated transformation of a medicinal plant Taraxacum platycarpum. Plant Cell Tiss Organ Cult. 2005:80(1):51-7.

12. Post J, van Deenen N, Fricke J, Kowalski N, Wurbs D, Schaller H, et al. Laticifer-specific cis-prenyltransferase silencing affects the rubber, triterpene, and inulin content of Taraxacum brevicorniculatum. Plant Physiol. 2012;158(3):1406.

13. Oscarsson L. Production of rubber from dandelion - a proof of concept for a new method of cultivation. Lund: LUND University; 2015.

14. Wahler D, Gronover CS, Richter C, Foucu F, Twyman RM, Moerschbacher $\mathrm{BM}$, et al. Polyphenoloxidase silencing affects latex coagulation in Taraxacum species. Plant physiol. 2009;151(1):334-46.

15. Gonzalez A, Zhao M, Leavitt JM, Lloyd AM. Regulation of the anthocyanin biosynthetic pathway by the TTG1/bHLH/Myb transcriptional complex in Arabidopsis seedlings. Plant J. 2008;53(5):814-27.

16. Vaghchhipawala Z, Rojas CM, Senthil-Kumar M, Mysore KS. Agroinoculation and agroinfiltration: simple tools for complex gene function analyses. Methods Mol Biol. 2011;678:65-76.

17. Koncz C, Schell J. The promoter of TL-DNA gene 5 controls the tissuespecific expression of chimaeric genes carried by a novel type of Agrobacterium binary vector. Mol Gen Genet. 1986;204(3):383-96.

18. Vickers CE, Schenk PM, Li D, Mullineaux PM, Gresshoff PM. pGFPGUSPlus, a new binary vector for gene expression studies and optimising transformation systems in plants. Biotechnol Lett. 2007;29(11):1793-6.
19. Nelson BK, Cai X, Nebenführ A. A multicolored set of in vivo organelle markers for co-localization studies in Arabidopsis and other plants. Plant J. 2007;51(6):1126-36

20. Cutler SR, Ehrhardt DW, Griffitts JS, Somerville CR. Random GFP::.CDNA fusions enable visualization of subcellular structures in cells of Arabidopsis at a high frequency. Proc Natl Acad Sci USA. 2000;97(7):3718-23.

21. Gao S-J, Damaj MB, Park J-W, Beyene G, Buenrostro-Nava MT, Molina J, et al. Enhanced transgene expression in sugarcane by co-expression of virus-encoded rna silencing suppressors. Plos One. 2013. https://doi.org/ 10.1371/journal.pone.0066046.

22. Clarke JD. Cetyltrimethyl ammonium bromide (CTAB) DNA miniprep for plant DNA isolation. Cold Spring Harb Protoc. 2009;2009(3):pdb.prot5177.

23. Jefferson RA, Kavanagh TA, Bevan MW. GUS fusions: beta-glucuronidase as a sensitive and versatile gene fusion marker in higher plants. Embo $\mathrm{J}$. 1987;6(13):3901-7.

24. Larkin PJ. Purification and viability determinations of plant protoplasts. Planta. 1976;128(3):213-6.

25. Li S, Cong Y, Liu Y, Wang T, Shuai Q, Chen N, et al. Optimization of agrobacterium-mediated transformation in soybean. Front Plant Sci. 2017. https://doi.org/10.3389/fpls.2017.00246.

26. Wroblewski T, Tomczak A, Michelmore R. Optimization of Agrobacteriummediated transient assays of gene expression in lettuce, tomato and Arabidopsis. Plant Biotechnol J. 2005;3(2):259-73.

27. Burris KP, Dlugosz EM, Collins AG, Stewart CN Jr, Lenaghan SC. Development of a rapid, low-cost protoplast transfection system for switchgrass (Panicum virgatum L.). Plant Cell Rep. 2016;35(3):693-704.

28. Musto S, Barbera V, Maggio M, Mauro M, Guerra G, Galimberti M. Crystallinity and crystalline phase orientation of poly(1,4-cis-isoprene) from Hevea brasiliensis and Taraxacum kok-saghyz. Polym Adv Technol. 2016;27(8):1082-90.

29. Arias M, Hernandez M, Remondegui N, Huvenaars K, van Dijk P, Ritter E. First genetic linkage map of Taraxacum koksaghyz Rodin based on AFLP, SSR COS and EST-SSR markers. Sci Rep. 2016;6:31031.

30. Luo Z, laffaldano BJ, Zhuang X, Fresnedo-Ramírez J, Cornish K. Analysis of the first Taraxacum kok-saghyz transcriptome reveals potential rubber yield related SNPs. Sci Rep. 2017;7(1):9939.

31. Zhang Y, laffaldano BJ, Zhuang X, Cardina J, Cornish K. Chloroplast genome resources and molecular markers differentiate rubber dandelion species from weedy relatives. BMC Plant Biol. 2017;17(1):34.

32. Lin T, Xu X, Ruan J, Liu S, Wu S, Shao X, et al. Genome analysis of Taraxacum kok-saghyz Rodin provides new insights into rubber biosynthesis. Natl Sci Rev. 2018;5(1):78-87.

33. Stolze A, Wanke A, van Deenen N, Geyer R, Prüfer D, Schulze Gronover C. Development of rubber-enriched dandelion varieties by metabolic engineering of the inulin pathway. Plant Biotechnol J. 2017;15(6):740-53.

34. van Beilen JB, Poirier Y. Guayule and Russian dandelion as alternative sources of natural rubber. Crit Rev Biotechnol. 2007;27(4):217-31.

35. Mukete B. Socioeconomic and ecological impact analysis of rubber cultivation in Southeast Asia. OA Lib J. 2016;3:1-11.

36. Craymer L. Dandelions ruin your front yard but could be the future of the rubber industry. Wall St J. 2018;2:2018.

37. Umar HY, Giroh DY, Agbonkpolor NB, Mesike CS. An overview of world natural rubber production and consumption: an implication for economic empowerment and poverty alleviation in Nigeria. J Hum Ecol. 2011. https://doi.org/10.1080/09709274.2011.11906350.

38. Global Natural Rubber Production All Set to Increase in 2019. (2019) https://www.gep.com/blog/mind/global-natural-rubber-production-allset-to-increase-in-2019: Global eProcure

\section{Publisher's Note}

Springer Nature remains neutral with regard to jurisdictional claims in published maps and institutional affiliations. 